\title{
Olhares da Psicologia acerca das violências contra as mulheres: incursões sob a Perspectiva de Gênero
}

\author{
Psychology's views on violence against \\ women: incursions from Gender Studies
}

\section{Claudiana Maria Santos' ${ }^{1}$ (1) Daniela Maria Barreto Martins 2 (1)}

${ }^{1}$ Autora para correspondência. Universidade do Estado da Bahia (Salvador). Bahia, Brasil. claudianasms@gmail.com ${ }^{2}$ Universidade do Estado da Bahia (Salvador). Bahia, Brasil. professoradanielamartins@gmail.com

RESUMO | INTRODUÇÃO: A violência contra a mulher é um fenômeno social crescente no Brasil, apresentando estatísticas alarmantes. Conforme o último balanço do Atlas Brasileiro de Violência, de 2019, o número de mulheres assassinadas em 2017 é o maior em 10 anos. Este trabalho busca refletir sobre a participação da Psicologia na busca de entendimento e formas de enfrentamentos, diante da série de quadros de violências que atingem as mulheres. OBJETIVO: Analisar, criticamente, as formas como a Psicologia tem abordado as violências contra as mulheres, em particular sob a perspectiva de gênero. METODOLOGIA: Foram analisadas diversas abordagens, a partir de registros produzidos por entidades reguladoras e associativas da profissão, bem como artigos científicos em Psicologia, publicados em periódicos nacionais, entre os anos de 2013 e 2017. O referencial teórico é a Psicologia Social Crítica. A abordagem metodológica, dadas as especificidades deste estudo, é a Revisão Integrativa. RESULTADOS: Autoras que trabalham na perspectiva da Psicologia Social Crítica têm contribuído de maneira substancial para a superação de uma Psicologia pautada em naturalização de papéis sociais, que dificulta a problematização da categoria gênero como socialmente construída. Dos trinta e dois artigos científicos analisados, vinte e três apontam gênero como categoria relevante, sendo que 11 destes dão ênfase a esta categoria como construto social e histórico que está a serviço das dicotomias homem-mulher, favoráveis à perpetuação das violências. CONCLUSÃO: Embora se reconheça a necessidade de aprofundar mais estudos, é notável o esforço da área para aproximação com a temática.

PALAVRAS-CHAVE: Psicologia social. Violência contra mulher. Gênero.

\begin{abstract}
INTRODUCTION: Violence against women is a growing social phenomenon in Brazil, presenting alarming statistics. According to the latest review of the Brazilian Atlas of Violence of 2019, the number of women murdered in 2017 is the highest in 10 years. This paper seeks to reflect on the participation of Psychology in the search for understanding and ways of coping with the series of violence that affects women. OBJECTIVE: To understand the ways in which Psychology has addressed violence against women, particularly from a gender perspective. METHODOLOGY: Approaches were analyzed based on a bibliographic research with material produced by professional regulatory and associative entities, as well as scientific articles in Psychology, published in national journals, between 2013 and 2017. The theoretical reference is Social Psychology. Criticism. The methodological approach, given the specificities of this study, is the Integrative Review. RESULTS: Authors who work from the perspective of Critical Social Psychology have contributed substantially to overcoming a Psychology based on the naturalization of social roles, which makes it difficult to problematize the gender category as socially constructed. Of the thirty-two scientific articles analyzed, twenty-three point to gender as a relevant category, 11 of which emphasize this category as a social and historical construct that is at the service of male-female dichotomies, favorable to the perpetuation of violence. CONCLUSION: Although it is recognized the need for further studies, it is remarkable the effort of the area to approach the theme.
\end{abstract}

KEYWORDS: Social psichology. Violence against woman. Gender.

Como citar este artigo: Santos, C. M., \& Martins, D. M. B. (2020). Olhares da Psicologia acerca das violências contra as mulheres: incursões sob a Perspectiva de Gênero. Revista Psicologia, Diversidade e Saúde, 9(1), 103-115. doi: 10.17267/2317-3394rpds.v9i1.2571 


\section{Introdução}

\section{Expressões das Violências contra as Mulheres}

A realidade da violência contra as mulheres, no Brasil, é absolutamente impactante, expressa num movimento de crescentes e alarmantes estatísticas ao longo dos anos. Até o ano de 2013, o Brasil ocupava a $5^{\text {a }}$ posição dentre outros 83 países do mundo em homicídio de mulheres. Em pesquisa de 2016, entre as mulheres brasileiras, $29 \%$ delas admitem já ter sofrido alguma forma de violência, afirmando que $43 \%$ dos casos aconteceram em ambiente doméstico (Instituto de Pesquisa Econômica Aplicada [IPEA] \& Fórum Brasileiro de Segurança Pública [FBSP], 2017); Conforme o último balanço do Atlas Brasileiro de Violência, do ano de 2019, o número de mulheres assassinadas em 2017 é o maior em 10 anos, com 4.936, um índice de 13 vítimas por dia (IPEA \& FBSP, 2019). Tais dados configuram um fator ainda mais grave, acentuando-se o fenômeno do feminicídio, se considerarmos que houve um aumento de $17,1 \%$ de homicídios ocorridos dentro de casa e aumento de $28,7 \%$ de mortes de mulheres por arma de fogo, no mesmo período.

O Balanço anual do Disque 180 - Central de Atendimento à Mulher (Ministério da Mulher, da Família e dos Direitos Humanos, 2016) informa ter realizado, atendimento a 1.133 .345 pessoas no ano de 2016. Em dados sistematizados do $1^{\circ}$ semestre de 2016, encontra-se o atendimento com 67.962 registros de relatos de violências, denunciados em $67,89 \%$ pelas próprias mulheres vitimadas. Na preponderância feminina encontrada entre as pessoas que buscam o serviço, mas não são as vítimas, as mulheres foram $80,76 \%$ de denunciantes. Dentre todas as violências, no quesito cor da vítima a preponderância está em $59,71 \%$ de mulheres negras que sofreram violências. O Dossiê violência contra as mulheres (Instituto Patrícia Galvão [IPG], 2015) traz informações de pesquisas mostrando altíssimas frequências de casos de violências: "um estupro a cada onze minutos", "uma mulher assassinada a cada duas horas", "503 mulheres vítimas de agressões a cada hora", e "cinco espancamentos a cada dois minutos".

A instituição da Lei Maria da Penha (Lei 11.340/06) é o marco brasileiro mais importante no regulamento jurídico das ações de enfrentamento às violências contra as mulheres, sobretudo destacando a violência doméstica e familiar, que, em seu bojo, constitui a forma de violência mais comum, e que mais crescem (Waiselfisz, 2015; IPEA \& FBSP, 2019). Conforme o já citado Atlas da Violência 2019 houve aumento de $17,1 \%$ dos homicídios ocorridos em casa contra redução de 3,3\% dos homicídios ocorridos fora de casa. As formas de configuração das violências doméstica e familiar, como dispostos na Lei, incluem as violências: física,psicológica, sexual, patrimonial, e moral,assim definidas:

I - a violência física, entendida como qualquer conduta que ofenda sua integridade ou saúde corporal;

II - a violência psicológica, entendida como qualquer conduta que Ihe cause dano emocional e diminuição da auto-estima ou que Ihe prejudique e perturbe o pleno desenvolvimento ou que vise degradar ou controlar suas ações, comportamentos, crenças e decisões, mediante ameaça, constrangimento,

humilhação, manipulação, isolamento, vigilância constante, perseguição contumaz, insulto, chantagem, ridicularização, exploração e limitação do direito de ir e vir ou qualquer outro meio que lhe cause prejuízo à saúde psicológica e à autodeterminação;

III - a violência sexual, entendida como qualquer conduta que a constranja a presenciar, a manter ou a participar de relação sexual não desejada, mediante intimidação, ameaça, coação ou uso da força; que a induza a comercializar ou a utilizar, de qualquer modo,

a sua sexualidade, que a impeça de usar qualquer método contraceptivo ou que a force ao matrimônio,

à gravidez, ao aborto ou à prostituição, mediante coação, chantagem, suborno ou manipulação; ou que limite ou anule o exercício de seus direitos sexuais e reprodutivos;

$I V$ - a violência patrimonial, entendida como qualquer conduta que configure retenção, subtração, destruição parcial ou total de seus objetos, instrumentos de trabalho, documentos pessoais, bens, valores e direitos ou recursos econômicos, incluindo os destinados a satisfazer suas necessidades;

$V$ - a violência moral, entendida como qualquer conduta que configure calúnia, difamação ou injúria. (Lei no 11.340, 2006, p. 19-20).

Por vezes, todas as formas descritas na Lei podem ocorrer concomitantemente, subjugando as mulheres a atos recorrentes e complexos de violências. Torna-se mais fácil identificar a ocorrência de violência física manifesta em agressões visíveis no corpo, em detrimento da identificação de atos de violência psicológica, sexual, moral e patrimonial. Muitas muIheres não reconhecem como violências os atos de maus tratos, abusos, manipulações, agressões verbais, ataques a sua imagem e integridade, e tantos 
outros excessos desrespeitosos à sua própria vontade e dignidade.

No rol dos atos violadores constam tanto as violências letais quanto aquelas não letais. No verso da Lei Maria da Penha estão descritas as formas de violências não letais, porém atenta-se para o fato de que, frente à contundência e periodicidade em que estas acontecem, tendem a incorrer em letalidade. Nesse último caso é a Lei do Feminicídio (Lei 13.104/15) que, em caráter específico, versa sobre a configuração da violência letal direcionada às muIheres. O Feminicídio se refere à morte de mulheres em razão de gênero, sempre associados a esse fator principal, e para fins de delimitar maiores identificações e estimativas das ocorrências, tem sido subdividido em diferentes categorias (IPEA \& FBSP, 2017; Onu Mulheres, Secretaria de Políticas para Mulheres/Ministério da Mulher, da Igualdade Racial e dos Direitos Humanos, \& Secretaria Nacional de Segurança Pública/Ministério da Justiça, 2016).

Conforme o documento Diretrizes para investigar, processar e julgar com perspectiva de gênero as mortes violentas de mulheres (Onu Mulheres, Secretaria de Políticas para Mulheres/Ministério da Mulher, da Igualdade Racial e dos Direitos Humanos, \& Secretaria Nacional de Segurança Pública/Ministério da Justiça, 2016), o Feminicídio pode ser classificado como: íntimo, não íntimo, infantil, familiar, por conexão, sexual sistêmico, por prostituição ou ocupações estigmatizadas, por tráfico de pessoas, por contrabando de pessoas, transfóbico, lesbofóbico, racista, por mutilação genital feminina. Já o Atlas da Violência (IPEA \& FBSP, 2017), sugere utilizar as categorias de Feminicídio: reprodutivo, doméstico e sexual.

Ainda sobre homicídio de mulheres (ou violência letal), vinculando-se o Mapa da violência (Waiselfisz, 2015) a informações da Pesquisa Nacional de Saúde PNS/2013 e do Instituto Brasileiro de Geografia e Estatística - IBGE, foi possível estabelecer comparações entre os índices de 1980 até 2013, um período equivalente a 33 anos. Em número de homicídios, por 100 mil habitantes, as taxas de vítimas foram de 2,3 em 1980 passando para 4,8 em 2013, representando um aumento exponencial de $111,1 \%$ no período.

Há que se analisar que, mesmo havendo lutas pelo direito das mulheres, estabelecimento de normativos jurídicos e políticas públicas com esse fim, sobretudo respaldando o combate das violências, historicamente, no decorrer de décadas diferentes, evidencia-se o crescimento no percurso desses crimes no Brasil. Entretanto, nessa linha histórica, no tocante a avaliação da atual vigência da Lei Maria da Penha, os dados apontam que antes dela havia maiores índices de homicídios: 7,6\% ao ano (1980-2006, antes da lei), e a partir da sua implementação, redução para 2,5\% ao ano (2006-2013) (Waiselfisz, 2015).

Lamentavelmente, os anos de 2017 e 2018 apresentam um inesperado e explosivo aumento de todas as formas de violência contra a mulher no Brasil, inclusos os feminicídios, que alcançaram mais de sete mil registros, identificados através do Disque 180 (Secretaria de Políticas para as Mulheres do Governo do Estado da Bahia, 2019). Este inesperado dado, no entanto, pode ser indicativo preocupante de um desinvestimento nas políticas públicas protetivas, bem como de um cenário social, em que significantes da violência, como a apologia à tortura e ao armamento, o machismo, o racismo, a homofobia, entre outros, tem tido passagem livre para manifestação, em que pese o enquadramento em crimes, como previsto na legislação brasileira.

\section{Questionamentos à Psicologia}

Diversos estudos, especialmente nas Ciências Sociais, apontam para a necessidade de adotar uma perspectiva de análise com base nas construções sociais e culturais em torno do ser homem e ser mulher em nossa sociedade. Perspectiva que define "gênero" como o produto desta construção e elege esta categoria como eixo central na análise de fenômenos sociais, que evidenciam a aceitação social do domínio dos homens sobre as mulheres, condição absolutamente favorável a concretização de violências de todas as ordens.

Quanto à Psicologia, em larga medida, acabou por ecoar ideias preconizadas por outros campos do saber intelectual, científico, religioso, e ideias incorporadas ao senso comum, afirmando diferenciações fixas entre os gêneros. Por muito tempo, e ainda hoje para algumas abordagens e interpretações, a Psicologia defendeu o funcionamento dos indivíduos baseado em diferenças sexuais, por via de classificações baseadas em características biológicas, associadas às diferenças de personalidade/performance dos sexos feminino e masculino. Uma visão que trata a diferença entre mulheres e homens por meio de características essencialistas, 
e a construção de subjetividades através da lógica androcentrista-heteronormativa-dominante.

Esta posição tem sido rebatida por diversos psicólogas/os, especialmente aqueles alinhados a uma Psicologia Social Crítica, que busca exatamente explorar as dimensões sócio-histórico-políticas dos fenômenos sociais, a fim de questionar e denunciar estruturas mantenedoras de domínios entre indivíduos e grupos, via de regra, produtoras de sofrimentos e injustiças sociais. Desta posição decorrem diversas interrogações aos fundamentos de práticas sociais e políticas, seus métodos de intervenção, suas implicações na socialização e individuação dos sujeitos, entre outros aspectos.

Em concordância com a Psicologia Social na linha dos Estudos de Gênero, se as subjetividades são tecidas nas interações sociais, problematizar as questões de gênero é preciso, tanto na identificação de como padrões psicossociais condicionam as mulheres ao sofrimento, quanto para constatar como são reforçados na sociedade.

A Psicologia, no auxílio a pessoas e coletividades em diversas condições, precisa estar preparada para lidar com as mulheres em sofrimento diante das violências, e para combater amplamente que ela seja perpetuada em todos os setores da vida, como algo naturalizado, em função das concepções distorcidas de papéis sociais do homem e da mulher. Esse movimento requer, ainda, que se concebam as mulheres em sua diversidade, observando o fenômeno em articulação com outros marcadores sociais (raça, classe, idade, religião e outros), que se sobrepõem nas desigualdades, com abrangência de fatores históricos, culturais, políticos e econômicos que estão em jogo.

No entanto, em que pese um esforço conjunto de Psicólogas/os e pesquisadores em Psicologia, no sentido de relacionar as construções de gênero ao grave quadro expresso nas estatísticas acima, esta perspectiva ainda é insuficientemente explorada. Os estudos existentes, via de regra, constatam números absolutamente inexpressivos de Psicólogas/os que consideram, em suas atuações e construções teórico-conceituais, a dimensão de gênero para abordar o problema das violências (Santos, 2016; Jesus e Galinkin, 2015; Lhullier\&Roslindo, 2013; Nogueira, 2001).

Desta forma, diante da série de sofrimentos de diversas ordens que recaem sobre as mulheres, em decorrência de quadros de violências, geradores de intenso e, por vezes permanentes, estados de sofrimento, o presente trabalho pretende contribuir com as perspectivas sociais críticas da profissão, que requerem a participação da Psicologia na busca de entendimento e de formas de enfrentamentos das violências contra as mulheres, e, portanto, o seu compromisso social. O objetivo deste estudo consiste em analisar, criticamente, as formas como a Psicologia tem abordado as violências contra as mulheres, em particular sob a perspectiva de gênero.

Para tal, foram analisadas diversas abordagens, a partir de registros produzidos por entidades reguladoras e associativas da profissão, bem como artigos científicos em Psicologia, publicados em periódicos nacionais, entre os anos de 2013 e 2017. O referencial teórico aqui adotado é o da Psicologia Social Crítica. A abordagem metodológica, dadas as especificidades deste estudo, a saber, a combinação de diversas fontes e referências, é a Revisão Integrativa.

\section{Abordagem Teórico metodológica}

A abordagem metodológica deste estudo, como já mencionado, é a Revisão Integrativa. Tal abordagem permite a combinação de dados diversos, da literatura teórica e empírica. Permite, ainda, integrar uma variedade de intenções: revisão de conceitos e teorias, análises críticas de problemas metodológicos, entre outros. (Souza, Silva e Carvalho, 2010). Desta forma, a adoção desta abordagem nos permitiu enriquecer as análises, associando a perspectiva teórica com achados na literatura empírica (artigos científicos), documentos e registros de entidades representativas e instituições e resultados de pesquisas de incidência do fenômeno na sociedade.

A Psicologia Social Crítica é o principal aporte teórico desta pesquisa, fomentando a compreensão do referido fenômeno social, incluindo o humano, através de análises sobre seu comportamento, relações sociais, e situações a que ele está sujeito, sob a condição social e histórica que o circunscreve e constitui (Bock, 2001).

Através da Psicologia Social Crítica compreendese que as disposições no campo social perfazem as histórias dos sujeitos construindo formas de subjetivação, já que estas não estão apartadas de contextos 
e estruturas sociais. Trata-se de um processo que ocorre dialeticamente entre tensões e contradições nas relações dos indivíduos com os dispositivos socioculturais e seus pares, incluindo-se dinâmicas de alienação, ao mesmo tempo em que é importante considerar possibilidades de transformação social pela ação crítico-reflexiva dos próprios indivíduos (Gruda, 2016).

O arcabouço teórico acessado para subsidiar o entendimento da problemática e reflexões ao longo do trabalho contempla as Teorias Feministas e os Estudos de Gênero, interligados com conhecimentos interdisciplinares, associando-os a importantes referenciais da Psicologia Social. Nesse campo dos estudos de Psicologia Social e Gênero há contribuições fundamentais de Conceição Nogueira e Jaqueline Jesus, estando a primeira mais voltada aos Estudos de Gênero e Sexualidades, e a segunda desenvolvendo estudos na mesma linha, ampliando-os na ênfase em estudo de Identidades de Gênero e relevância da categoria cor/raça.

A respeito da caracterização de situações de violência cometidas contra as mulheres, a Lei Maria da Penha (Lei 11.340/2006) será o instrumento principal para definição das formas de violência doméstica, entre as quais se destacam neste estudo: física, psicológica, sexual, patrimonial e moral (Lei $\left.n^{\circ} 11.340,2006\right)$. $E$, tendo em vista a crescente de agravos dessas situações, complementar-se-á esse rol com as determinações da Lei do Feminicídio (Lei 13.104/2015), agregando a qualificação de morte violenta de mulheres em razões de gênero (Lei no 11.340, 2006).

A pesquisa tem caráter qualitativo. Embora a pesquisa seja predominantemente qualitativa, oferece alguns dados quantitativos de trabalhos e produções científicas, observados apenas para fins de análise. A utilização das técnicas de pesquisa documental e bibliográfica serviu de base para realização da coleta de dados e informações, respectivamente em fontes secundárias. Dessa forma, foram acessadas diversas fontes de pesquisa buscando-se respaldar questões importantes para compreensão das situações de violências contra as mulheres. A grande maioria das fontes de pesquisa foram encontradas em meio digital e/ ou eletrônico.

A coleta dos dados foi realizada em quatro fontes de informação. Primeiro procedeu-se com a análise das normas legais institucionais direcionadas ao enfrentamento da violência contra as mulheres, dentre convenções, leis, programas, políticas, campanhas, conferências, além do acesso a fontes de dados estatísticos atestando a realidade do fenômeno.

Em seguida, para conhecimento das normatizações e aproximações em torno do tema, proferidas pelo Sistema de Conselhos de Psicologia ao longo dos anos, enquanto instância orientadora da profissão, sobretudo, pesquisou-se sobre seu posicionamento e materiais de construção própria através de: resoluções; referências técnicas para atuação de psicólogas/os; notas técnicas, de repúdio, públicas ou de posicionamento; publicações; moções de apoio; campanhas; cartas abertas; atos de formação de Comissões e Grupos de Trabalho; articulações estratégicas e intersetoriais.

Depois, prosseguiu-se com a identificação de artigos científicos do campo amplo da psicologia, publicados em periódicos nacionais, no período equivalente aos anos de 2013 a 2017, discutindo sobre problemáticas em torno das violências contra mulheres, no sentido de acompanhar como tem sido pautada as discussões, especialmente no que tange a inclusão de aspectos que apontam para a compreensão social do fenômeno levantadas nessa pesquisa. A base de dados online acessada para pesquisa foi a Biblioteca Virtual em Saúde - Psicologia (BVS-Psi Brasil), plataforma que reúne materiais publicados na área, consolidando dados de diversas bases bibliográficas importantes, como: PePSIC, SCiELO e LILACS. O levantamento dos artigos foi feito utilizando como critério a associação dos seguintes termos como indexadores de busca: "psicologia e violência"; "mulheres e violência"; "violência e gênero"; "violência e doméstica"; "feminicídio". Foram encontrados ao todo 82 artigos publicados de 2013 a 2017, tratando sobre o tema da pesquisa. Foram descartados aqueles produzidos em escrita conjunta com outra área de estudo (08). E, depois de conferidas também as repetições ocorridas (42), foram finalmente escolhidos 32 artigos para análise.

Por fim, tendo como aspecto importante incluir análises com referencial da Psicologia Social Crítica, conforme orientação do presente estudo, com o propósito de conhecer o andamento dos debates e produções no referido campo, foram acessadas fontes de informações da Associação Brasileira de Psicologia Social - ABRAPSO, do período entre 2013 a 2017, considerando as publicações da área em revista científica, livros, e apresentação de trabalhos 
constantes nos Anais dos Encontros Nacionais. Nesse caso foi necessário modificar a estratégia de busca por indexadores, em decorrência de não ter acesso a um sistema que permitisse cruzamentos de dados na procura, mas sim o acesso a documento eletrônico/ digital dos referidos Anais da ABRAPSO. A procura foi, então, por trabalhos que trouxessem os termos "violência", "violência de gênero", "violência doméstica"; "violência contra a mulher"; "feminicídio.".

Os resultados destas incursões acerca da percepção que os psicólogas/os, em seu amplo espectro de atuação, têm desenvolvido sobre o problema das Violências contra as mulheres, estão aqui organizados em duas dimensões: "Psicologia e Gênero", em que se busca compreender como os psicólogas/os têm assimilado esta perspectiva em seus estudos e práticas, bem como a interação entre as teorias psicológicas (as consolidadas e as que estão em construção) e a teoria feminista; e "Psicologia e Violências contra as mulheres: interações e indagações diante da perspectiva de gênero" - em que se busca analisar, a partir das fontes consultadas, o alcance da perspectiva de gênero nos estudos sobre a violência contra mulher, no âmbito da Psicologia, dentro da delimitação já definida acima para este estudo.

\section{Psicologia e Gênero}

É evidente a importância da perspectiva de gênero para compreensão em profundidade do fenômeno social das violências contra as mulheres. Ao situar gênero enquanto um estruturante social e relacional construído historicamente, tal perspectiva revela a formação de determinados padrões na concepção das ideias de feminino e masculino, demarcando desigualdades reais entre mulheres e homens. Estas perspectivas denunciam como essas formações, ao serem manipuladas por interesses de grupos hegemônicos, contribuem para instaurar regimes de violências de gênero e outras correlatas, afetando principalmente as mulheres, em sua diversidade de contextos, raça, classe, sexualidade e identidade de gênero.
Nogueira (2001) aponta que ao longo da história da Psicologia foram desenvolvidos estudos e pesquisas afirmando as diferenças sexuais como fator definidor das características dos indivíduos, em termos de "temperamento" ou personalidade'. Então, sustentava-se que entre os sexos cada qual desenvolveria níveis diferentes em padrões como sentimentos, interesses, atitudes e comportamentos. Demarcando status de integração na sociedade, essas diferenças estariam alicerçadas nas divisões para atuação dos sujeitos em dualidades nos âmbitos público e privado, família e trabalho produtividade e vida doméstica.

O movimento da segunda onda do Feminismo teceu críticas incisivas a essas concepções da Psicologia, à medida que desde sempre tais estudos apresentavam resistência à aceitação das considerações feministas sobre os seus cânones teóricose este fato estaria possivelmente associado à ênfase positivista que dominou esta ciência. Contudo, embora sendo o Feminismo um movimento de posicionamento político que se opunha à neutralidade da ciência, esteve a questionar não o estatuto da ciência, mas sim os métodos científicos utilizados, e assim "na psicologia, as feministas desafiam o que conhecemos acerca de homens e mulheres, questionando os resultados das pesquisas convencionais que contribuíram largamente para o significado de género, implícito no nosso dia-a-dia". (Nogueira, 2001, p.11-16).

Entretanto, a autora retoma ressaltando que mesmo com a abertura da Psicologia para dar outra direção aos estudos associados ao gênero, por vezes, algumas ideias sob enfoque feminista encontram certa oposição e resistências. Ainda se segue com a realização de trabalhos naturalizando as diferenças sexuais, seus desdobramentos individuais e para a vida em sociedade. Também para Santos (2016); Jesus e Galinkin (2015), os estudos de gênero na área da Psicologia são insuficientes. Tais autoras declaram que costuma prevalecer visões reforçando padrões estereotipados, traçando estreita correlação entre diferenças biológicas e psicossociais.

\footnotetext{
${ }^{1}$ A exemplo das concepções sustentadas pela Psicologia do Desenvolvimento, conforme tratado por Oliveira e Madureira (2014), em estudo de revisão literária da área. Para as autoras, esta abordagem primou pela construção teórica baseada na normatividade. Portanto, sustentando ideias essencialistas e de desigualdades de gênero relacionadas ao desenvolvimento humano de homens e mulheres, que seriam consolidadas no plano das relações sociais.
} 
Em pesquisa (Lhullier \& Roslindo, 2013) que traça o perfil das psicólogas brasileiras, do total de mil trezentos e trinta e uma psicólogas entrevistadas, somente treze declararam tratar questões de gênero em suas práticas e/ou estudos, levando as autoras à conclusão do "quanto às relações de poder entre os sexos ainda são pouco presentes como um problema de pesquisa e ação para a Psicologia, da mesma forma que os temas do feminino e da mulher" (p.24-25).

Em contrapartida, a proposição de discussões de gênero em novas vertentes tem tido destaque na Psicologia Social. Santos (2016), ao reconhecer uma maior aproximação com o tema conduzido na área da Psicologia Social, destaca a necessidade de abarcar estudos de gênero em todos os campos da Psicologia, diante da significância dos temas relacionados para a formação acadêmica, atuação profissional, calcadas na atenção aos Direitos Humanos.

A esse respeito Jesus e Galinkin (2015) ressaltam a Psicologia Social como área em grande potencial para discutir essas questões, por conta da aproximação com estudos sociológicos, e, portanto, capaz de tecer uma perspectiva sobre gênero que reconheça o seu contexto sócio-histórico e cultural, embora sejam necessários maiores estudos psicossociais e produções tratando da temática. Com relação aos estudos de gênero que acontecem nas vertentes psicológica e sociológica, nota-se a indiscutível superioridade da segunda sobre a primeira, uma vez que a categoria gênero para a sociologia já está bem consolidada como uma categoria social e/ou base estruturante da sociedade. Os anos 90 são tomados como fase expoente de abertura na área, "com a inclusão de estudos sobre masculinidade e discussão com o movimento de Lésbicas, Gays, Bissexuais, Travestis e Transexuais - LGBT, sobre orientação sexual e questões de gênero aplicadas às diferentes realidades dessas populações"(Jesus \& Galinkin, 2015, p.94)

Nogueira (2001) descreve uma Psicologia Social influenciada pelo Feminismo na construção de uma "psicologia empiricista feminista"e do "pós-empiricismo feminista", com diferentes linhas sustentando a defesa da ideia de gênero construído socialmente (p.23). Com relação à produção científica no referido campo, Jesus e Galinkin (2015, p. 93-95-98) afirmam que, mesmo em pouco número a Psicologia Social contemporânea brasileira tem demarcado espaço através de pesquisa. Expressam tais afirmações com os seguintes números: no período entre os anos de
1974 - 2011, de 12 livros locais ou traduzidos para utilização nas formações acadêmicas em disciplinas de Psicologia Social, somente um livro reservava espaço para abordar estudos de gênero.

Quanto à publicação de artigos, de 43 encontrados no período entre 1988 - 2012. 7\% são dos fins dos anos 1980 ao início do século XXI, 74,4\% são da primeira década do século XXI e 18,6\% do início da segunda década até 2012. (Nogueira, 2001) Estes resultados evidenciam o crescente interesse da Psicologia, em particular da Psicologia Social, na abordagem de gênero.

É relevante destacar o quanto passa a ser importante essa aproximação da Psicologia com os Estudos de Gênero, compreendendo o aspecto de composição estrutural das sociedades e relações, em que a categoria gênero figura como um elemento chave na forma como se estabeleceram as disposições sociais, políticas, culturais e econômicas para os sujeitos mulheres e homens. E nessa interação, como são constituídos padrões de subjetividades e comportamentos esperados. Esses aspectos são aqui considerados cruciais para a abordagem da violência contra mulher.

\section{Psicologia e Violências contra as mulheres: interações e indagações diante da perspectiva de gênero}

Entre os 32 artigos científicos eleitos para análise, encontram-se diferentes formas de apresentação dos estudos das violências contra as mulheres: revisão teórica, análise da prática profissional, relato de experiência, pesquisa de campo, pesquisa-ação, estudo de caso, análise fílmica / pesquisa documental. As violências contra as mulheres são analisadas em contextos diversos, com atuação da Psicologia nas áreas da saúde, socioassistencial, jurídica, e segurança pública. Quanto à inclusão da perspectiva de gênero, é interessante notar que muitas/os autoras/os admitem essas marcações de gênero como imbricadas na constituição social do fenômeno, embora nem sempre problematizando como de fato se traduziriam na configuração dessas permanentes violações.

No rol dessas produções foi possível identificar entre 23 artigos certo movimento em reconhecimento e de alguma forma sinalização de aspectos ligados ao gênero (Bittar \& Kohlsdorf, 2013; Bruhn \& Lara, 2016; Cavalcante et al., 2017; Cortez et al., 2013; Dias, \& Neves, 2014; Farinha \& Souza, 2016; 
Fernandes et al., 2014; Griebler \& Borges, 2013; Guimarães \& Pedroza, 2015; Lima \& Méllo, 2013; Meinhardt \& Maia, 2015;Oliveira, 2014; Porto \& Bucher-Maluschke, 2014; Ramos, 2013; Razera \& Falcke, 2014; Romagnoli, 2015a;Romagnoli, 2015b; Rosa \& Falcke, 2014; Sant'Anna \& Penso, 2015; Scarpati et al., 2014; Silva et al., 2016; Souza\&Sousa, 2015; Vigário\& Paulino-Pereira, 2014.), e 09 artigos em que não se admite essa perspectiva. (Borges et al., 2017; Garcia, 2013; Guzzon \& Yoshida, 2017; Hermel \& Drehmer, 2017; Lacerda \& Costa, 2013; Paim \& Falcke, 2016; Sá \& Werlang, 2013; Santeiro et al., 2017; Zancan et al., 2013)

Dos 23 artigos condizentes, 11 deles consideram realmente o gênero como uma categoria social importante para compreensão do fenômeno (Bittar \& Kohlsdorf, 2013; Cavalcante et al., 2017; Griebler \& Borges, 2013; Guimarães \& Pedroza, 2015; Meinhardt \& Maia, 2015;Oliveira, 2014; Porto \& Bucher-Maluschke, 2014; Romagnoli, 2015b;Sant'Anna \& Penso, 2015; Silva et al., 2016; Vigário\& PaulinoPereira, 2014), enquanto apenas 07 dentre esses trabalhos realizam em maior proporção análises mais críticas, indo além ao aprofundar as discussões dos dados de suas pesquisas sobre as violências em associação direta com as construções de gênero.

Embora algumas discussões consigam relacionar a relevância de vincular o gênero às compreensões sobre a temática, poucos de fato se predispõem a recorrer a esse caminho para embasamento nas análises dos seus estudos. Se entendemos que a raiz do problema das desigualdades e violações dos direitos das mulheres está justamente nas construções sociais acerca de gênero, que historicamente define papéis e lugares de poder, é preciso concordar que o caminho central para enfrentamento dessas violências é a problematização e desconstrução desses lugares, a partir dos estudos de gênero.

Então, de fato, apenas nos 11 estudos supracitados há concordâncias obre o construto de gênero como uma importante categoria de análise histórica e social, abarcando dimensões cultural, relacional, contextual e política. Admite-se então que estas construções estariam a serviço de lógicas dicotômicas na definição de atribuições, utilizando-se das diferenciações sexuais biológicas para determinar relações e papéis demarcados para homens e mulheres, enquadrando-os em perfis fixos de comportamento, de acordo com as expectativas da sociedade sobre cada um deles/as. Este processo de padronização cria uma margem segura para quaisquer discriminações baseadas em preconceitos, estigmas e estereótipos contra quem ousar sair da linha.

Outro aspecto destacado nesses estudos é a predominância de relações de poder mediando as relações de gênero, em associação às conhecidas tensões no estabelecimento de posturas de dominação e controle do feminino pelo masculino. Tais problemas são associados à existência das instituições do patriarcado, machismo, racismo, sexismo, heteronormatividade, como condensadores para manter a condição de subordinação destinada às mulheres.

Nos 09 trabalhos em que não se admite essa perspectiva (Borges et al., 2017; Garcia, 2013; Guzzon \& Yoshida, 2017; Hermel \& Drehmer, 2017; Lacerda \& Costa, 2013; Paim \& Falcke, 2016; Sá \& Werlang, 2013; Santeiro et al., 2017; Zancan et al., 2013), encontram-se diferentes enfoques para enquadramento dos fatores que levariam ao estado das violências. As abordagens com foco interacional orientam-se por afirmar que as mulheres também cometem violências, que aconteceriam mutuamente entre elas e seus parceiros. Acentuam que os fatos sempre aconteceram por investimento de ambas as partes numa "perspectiva relacional" do casal, em que o homem ou a mulher podem alternar em ser agressores/as ou vítimas, a depender de quais formas de vínculos são constituídos pelos casais. Assim minimizam, inclusive, os dados que apontam para maiores incidências e danos que recaem sobre elas, estando ou não em relações afetivo-sexuais, pois as violências a elas dirigidas acontecem diversa e amplamente na sociedade.

Por essa via, ainda se faz o questionamento das visões que situam os homens como agressores e as mulheres como vítimas, como se simplesmente houvesse interesses terceiros (do debate social, e talvez dos estudos de gênero) de enfatizar os homens ou representantes do "sexo" masculino sempre como potenciais agressores. Importante assinalar que esses estudos assim tentam dirigir a compreensão do problema para um foco mais privado, pontual, mesmo quando ratificam com algum dado o fato das violências contra as mulheres serem mais predominantes. Esse norte de pensamento é associado a noções que concebem a existência apenas do que se poderia caracterizar como uma violência conjugal. 
Na direção desses estudos, outras causas sinalizadas têm como base do problema das violências aspectos subjetivos inerentes às mulheres, que as tornariam mais suscetíveis a estarem sujeitas a essas condições, contudo nem sempre contextualizando as subjetivações que ocorrem em interação social. Uma segmentação que embasa justificativas sobre a primazia das causas intrapsíquicas desfavoráveis ou disparadoras, predisposição a transtornos mentais da vítima ou agressor, patologização com enquadres individualistas, e, portanto sem considerar, com efeito, os fatores sociais e condições históricas que propiciam a constância das violações e/ou as variadas violências que as mulheres, como um todo, passam sistematicamente por toda a vida.

Entretanto, em que pese a importância para a Psicologia de atentar para as condições subjetivas face às violências contra as mulheres e todo sofrimento relacionado, considera-se que as imposições de gênero estão em primeiro plano para compreensão da raiz social do problema, estando talvez outros aspectos de personalidade, recursos internos de enfrentamento emocional, ou de recorrente fragilização do gênero feminino em segundo plano, como delas decorrentes e não o contrário.

Ainda dentre os trabalhos que buscam confrontar a perspectiva de gênero, está aabordagem da causa intergeracional definindo as violações como simplesmente atreladas ao aprendizado, com a reprodução das violências sofridas em contexto familiar repercutindo por gerações. Sob esse ponto de vista, perdese a perspectiva de que todas as instituições sociais, logo também as famílias, estão sujeitas às socializações baseadas às relações de poder entre os gêneros.

Ademais, retomando na linha das produções que contemplam análises sob a categoria de gênero, há dois estudos (Lima, \& Méllo, 2013; Griebler \& Borges, 2013) que propõem a partir dessas discussões confrontar as formulações estabelecidas em tornodo gênero masculino, e desconstrução dessas ideias, para que seja possível agregar às pautas de debates ponderações sobre o lugar do agressor. Neste caso, o agressor é visto como aquele que precisa ser ressocializado para compreender o status das disparidades e do pensamento social que embasa suas práticas, independente e/ou em paralelo das devidas sanções decorrentes dos crimes de violências praticados contra as mulheres. Implica a necessidade de conscientizá-los sobre elementos que permeiam o seu comportamento e propiciar reflexão crítica permanente para superação das violências.

Considerando a inserção da Psicologia em campos diversos, 06 estudos fazem críticas a discursos promovidos nas esferas da saúde, socioassistencial, jurídica, segurança pública e outras instituições, como reforçadores das relações de poder e desigualdades de gênero (Meinhardt \& Maia, 2015; Oliveira, 2014; Romagnoli, 2015a; Romagnoli, 2015b; Sant'Anna \& Penso, 2015; Silva et al., 2016). Alegam que os saberes e poderes instituídos costumam validar as formulações sobre as mulheres com representação social negativa, estigmatizante e discriminatória, inclusive diretamente diante de casos e atendimentos às vítimas de violências. Denunciam práticas repletas de preconceito e invisibilidades das situações de mulheres que recorrem a esses serviços, revitimizando-as, diante do fenômeno social das violências. Sugerem, então, que reflexões pautadas nas questões de gênero são propícias a um novo entendimento, pois, embora muitas vezes os ordenamentos normativos tenham avançado na proteção, na prática cotidiana desses serviços o entendimento sobre o problema e a ação sobre o mesmo pode acontecer de maneira equivocada, por exemplo aumentando a carga de culpabilização das mulheres.

Apesar da alusão às teses de gênero feitas na maioria dos artigos, inclusive com referência a importantes estudiosas/os da temática ${ }^{2}$, e de certas menções reconhecendo o importante papel da luta do movimento feminista nessa interlocução, apenas 03 deles (Farinha \& Souza, 2016; Souza \& Sousa, 2015; Vigário \& Paulino-Pereira, 2014) ratificam a indispensabilidade de realizar maior aproximação da Psicologia com os Estudos de Gênero, propriamente dito, e as Violências, na diversidade de questões e interdisciplinaridades que eles abraçam. 


\section{Considerações Finais}

A violência contra a mulher é um problema complexo e com raízes sociais profundas, relacionando variados fatores. E, sobretudo remonta aspectos históricos de dominação de grupos sobre outros, que estrutura as sociedades e, portanto, as desigualdades vistas entre homens e mulheres.

No que diz respeito às violências contra as mulheres no Brasil, há o recrudescimento da situação, demandando maior atenção dos poderes públicos, de profissionais de diferentes áreas, e urgente mudança da mentalidade machista para lidar com o problema. Trata-se de violação de direitos humanos afetando a dignidade e liberdade das mulheres, ainda configurando alarmante caráter epidemiológico por trazer sérios danos à saúde integral, dentre outras consequências.

Dada a amostra pesquisada nesse trabalho, percebe-se que entre os estudos apresentados em artigos científicos de Psicologia, tratando sobre o tema das violências contra as mulheres, para a maioria, a perspectiva de gênero perpassa em algum nível o fenômeno, embora nem sempre aprofundem os debates nesta direção. Evidencia-se certa abertura nesse sentido, em busca desse reconhecimento. Admite-se já ser favorável a aproximação cada vez maior da Psicologia com estes temas, e, portanto, da busca por melhor entendimento sobre as condições em que eles se estabelecem na formação social.

Contudo, um longo caminho ainda há de ser percorrido frente ao crescimento do número de mulheres em situações de violências. É imprescindível refletir criticamente e agir no enfrentamento diante desse quadro dramático, o que exige um posicionamento mais comprometido da Psicologia como ciência e prática profissional.

Entretanto, como sinalizam algumas/os autoras/os de referência, no que diz respeito à produção teórico-científica ainda são insuficientes Estudos de Gênero e Psicologia, o que tem dificultado adentrar sobre essas situações de violências, numa perspectiva social que atente para as problemáticas de gênero e interseccionalidades, com outros marcadores de vulnerabilidades sociais. Além disso, há contradições em certas abordagens, que privilegiam pautar o desenvolvimento psicológico situando diferenciações sexuais, na tendência de essencializar e cristalizar padrões comportamentais, e consequente atuação em papéis e relações sociais.

Neste sentido, consideramos que o presente trabalho alcançou o seu objetivo, no que diz respeito às análises das abordagens em Psicologia sob a perspectiva de gênero, porém tem alcance limitado quanto às questões de interseccionalidade com os marcadores sociais de raça, classe, geração, entre outros, de que se depreende a necessidade de avanço em próximos estudos, nesta perspectiva

Por fim, este trabalho destaca um posicionamento político para Psicólogas e Psicólogos, e a necessidade de seguir atualizando-se diante das discussões de gênero e violências, tão caras nos últimos tempos. Esta necessidade torna-se ainda mais urgente diante da atual conjuntura política no país, onde acrescem posturas reacionárias de alguns grupos e atores sociais, buscando validar retrocessos no avanço das garantias de direitos humanos e liberdades fundamentais, dentre outros quesitos, comprometendo deliberadamente os direitos das mulheres.

Em contrapartida, diante das ameaças fascistoides contra esses direitos, crescem as iniciativas de enfrentamento pelos movimentos feministas e pelo protagonismo das mulheres em suas lutas, na organização política de resistência de mulheres negras, de periferia, lésbicas, bissexuais, trans, acadêmicas, e tantas outras. E assim, em alinhamento às demandas correntes, embora em movimento ainda discreto, cresce o próprio interesse da Psicologia em torno temática. As ações por parte da categoria profissional de Psicólogas/os, em articulações e mobilizações, com proposição de debates, a atividades dos GTs em torno do tema, o crescente desenvolvimento de pesquisa e publicações da área evidenciam maior comprometimento. A solidez e o impacto destas novas articulações deverão ser melhor analisadas num momento posterior, como parte integrante da pesquisa ora apresentada.

\section{Contribuições das autoras}

Martins, D. M. B. participou da orientação, concepção, delineamento, análise e revisão crítica e redação do artigo científico. Santos, C. M. S. participou da concepção, delineamento, coleta e análise dos dados da pesquisa, interpretação dos resultados, e redação do artigo científico. 


\section{Conflitos de interesses}

Nenhum conflito financeiro, legal ou político envolvendo terceiros (governo, empresas e fundações privadas, etc.) foi declarado para nenhum aspecto do trabalho submetido (incluindo, mas não se limitando a subvenções e financiamentos, participação em conselho consultivo, desenho de estudo, preparação de manuscrito, análise estatística, etc.).

\section{Referências}

Bittar, D., \& Kohlsdorf, M. (2013). Ansiedade e depressão em mulheres vítimas de violência doméstica. Psicologia Argumento, 31(74), 447-456. Recuperado de https:// periodicos.pucpr.br/index.php/psicologiaargumento/ article/view/20447/19707. doi: 10.7213/psicol. argum.31.074.DS08

Bock, A. M. B. (2001). A Psicologia Socio-Histórica: uma perspectiva crítica em Psicologia. In A. M. B. Bock, M. G. M, Golçalves, \& O. Furtado (orgs). Psicologia Socio-Histórica: uma perspectiva crítica em Psicologia. (3a ed., Cap. 1). São Paulo: Cortez.

Borges, L. M., Lodetti, M. B., \& Girardi, J. F. (2017). Homicídios conjugais: o que dizem os processos criminais. Psicologia Argumento, 32, 197-208. Recuperado de https://periodicos. pucpr.br/index.php/psicologiaargumento/article/ view/20635/pdf. doi: 10.7213/psicol..argum.32.s02.A018

Bruhn, M. M., \& Lara, L. (2016). Rota crítica: a trajetória de uma mulher para romper o ciclo da violência doméstica. Revista Polis Psique, 6(2), 70-86, 2016. Recuperado de http:// pepsic.bvsalud.org/pdf/rpps/v6n2/n6a05.pdf

Cavalcante, L. M., Gomes, C. A. R., \& Moreira, L. E. (2017). Uma análise das construções de gênero na jurisprudência alagoana. Revista Polis Psique, 7(2), 68-83. Recuperado de https://seer.ufrgs.br/PolisePsique/article/view/66113/pdf. doi: $\underline{10.22456 / 2238-152 X .66113}$

Cortez, M. B., Cruz, G. V., \& Souza, L. (2013). Violência conjugal: desafios e propostas para a aplicação da lei Maria da Penha. Psico, 44(4), 499-407. Recuperado de http:// revistaseletronicas.pucrs.br/ojs/index.php/revistapsico/ article/view/11542/10842

Dias, A. S. F., \& Neves, A. S. (2014). A constituição do vínculo conjugal violento: estudo de caso. Vínculo, 11(1), 8-15. Recuperado de http://pepsic.bvsalud.org/pdf/vinculo/ v11n1/n1a03.pdf

Farinha, M. G., \& Souza, T. M. C. (2016). Plantão psicológico na delegacia da mulher: experiência de atendimento sócioclínico. Revista da SPAGESP, 17(1), 65-79. Recuperado de http://pepsic.bvsalud.org/pdf/rspagesp/v17n1/v17n1a07. pdf
Fernandes, G. B., Gaia, V. O., \& Assis, C. L. (2014). Estratégias de enfrentamento da violência de gênero em mulheres de ji-Paraná (RO). Mudanças, 22(2), 1-14. Recuperado de: https://www.metodista.br/revistas/revistas-ims/index.php/ MUD/article/view/4460/4883. doi: 10.15603/2176-1019/ mud.v22n2p1-14

Garcia, E. L. (2013). Tatadrama: A violência mantida em segredo que emerge na boneca de pano. Revista Brasileira de Psicodrama, 21(1), 165-172. Recuperado de http://pepsic. bvsalud.org/pdf/psicodrama/v21n1/a13.pdf

Griebler, C. N., \& Borges, J. L. (2013). Violência contra a mulher: perfil dos envolvidos em boletins de ocorrência da Lei Maria da Penha. Psico, 44(2), 215-225. Recuperado de http://revistaseletronicas.pucrs.br/ojs/index.php/ revistapsico/article/view/11463/9640

Gruda, M. P. P. (2016). Breves considerações, comentários e ideias acerca de uma Psicologia Social Crítica. Pesquisas e Práticas Psicossociais, 11(2), 514-526. Recuperado de http://pepsic. bvsalud.org/scielo.php?script=sci_arttext\&pid=S1809$89082016000200019 \&$ Ing=pt\&nrm=iso

Guimarães, M. C., \& Pedroza, R. L. S. (2015). Violência contra a mulher: problematizando definições teóricas, filosóficas e jurídicas. Psicologia \& Sociedade, 27(2), 266-266. Recuperado de http://www.scielo.br/scielo. php?script=sci_arttext\&pid=S0102-71822015000200256. doi: 10.1590/1807-03102015v27n2p256

Guzzon, J. T., \& Yoshida, E. M. P. (2017). Avaliação de mudança em mulheres vítimas de violência. Psicologia Argumento, 31(74). Recuperado de https://periodicos.pucpr.br/index. php/psicologiaargumento/article/view/20189/19479. doi: 10.7213/psicol.argum.31.074.DS05

Hermel, J. S., \& Drehmer, L. B. R. (2017). Repercussões da violência intrafamiliar: Um estudo com mulheres em acompanhamento psicológico. Psicologia Argumento, 31(74), 437-446. Recuperado de https://periodicos. pucpr.br/index.php/psicologiaargumento/article/ view/20395/19659. doi: 10.7213/psicol.argum.31.074.DS07

Instituto de Pesquisa Econômica Aplicada, \& Fórum Brasileiro de Segurança Pública (2017). Atlas da violência 2017. Rio de Janeiro: Ipea; FBSP. Recuperado de http://www.ipea.gov. br/portal/images/170609_atlas_da_violencia_2017.pdf

Instituto de Pesquisa Econômica Aplicada, \& Fórum Brasileiro de Segurança Pública (2019). Atlas da violência 2019. Rio de Janeiro: Ipea; FBSP. Recuperado de http://www. ipea.gov.br/portal/images/stories/PDFs/relatorio_ institucional/190605_atlas_da_violencia_2019.pdf

Instituto Patrícia Galvão (2015). Dossiê violência contra as mulheres [Site]. Recuperado de https://dossies. agenciapatriciagalvao.org.br/violencia/ 
Jesus, J. G., \& Galinkin, A. L. (2015). Gênero e Psicologia Social no Brasil: entre silêncio e diálogo. Barbarói, 43, 90-103. Recuperado de https://online.unisc.br/seer/index.php/ barbaroi/article/view/4482/4410. doi: 10.17058/barbaroi. v0i0.4482

Lacerda, L., \& Costa, N. (2013). Relação entre comportamentos emocionais ciumentos e violência contra a mulher. Revista Brasileira de Terapia Comportamental e Cognitiva, 15(3), 21-36. Recuperado de http://pepsic.bvsalud.org/pdf/rbtcc/ v15n3/v15n3a03.pdf

Lei $n^{\circ} 11.340$, de 7 de agosto de 2006. Cria mecanismos para coibir a violência doméstica e familiar contra a mulher. Recuperado de http://www.planalto.gov.br/ccivil_03/_ ato2004-2006/2006/lei//11340.htm

Lima, M. L. C., \& Méllo, R. P. (2013). Algumas considerações sobre os homens no contexto da violência contra a mulher. Psicologia Argumento, 31(74), 425-435. Recuperado de https://periodicos.pucpr.br/index.php/ psicologiaargumento/article/view/20295/19567. doi: 10.7213/psicol.argum.31.074.DS06

Lhullier, L. A., \& Roslindo, J.J. (2013). As psicólogas brasileiras: levantando a ponta do véu. In L. A. Lhullier, (org.). Quem é a Psicóloga brasileira? Mulher, Psicologia e Trabalho. Brasília: Conselho Federal de Psicologia.

Ministério da Mulher, da Família e dos Direitos Humanos (2016). Balanço anual do Disque 180 - ano 2016. Recuperado de https://www.mdh.gov.br/navegue-por-temas/ politicas-para-mulheres/arquivo/assuntos/violencia/ ligue-180-central-de-atendimento-a-mulher/balancoanual-180_2016.pdf/view . doi: 10.7213/psicol..argum.32. s02.A018

Nogueira, C. (2001). Feminismo e discurso do gênero na psicologia social. Psicologia e Sociedade, 13(1), 107-128. Recuperado de http://repositorium.sdum.uminho.pt/ handle/1822/4117

Oliveira, É. C. S. (2014). Eu também sei atirar: reflexões sobre a violência contra as mulheres e metodologias estético políticas. Psicologia Ciência e Profissão, 34(3), 573573. Recuperado de http://www.scielo.br/pdf/pcp/ v34n3/1982-3703-pcp-34-03-0555.pdf. doi: 10.1590/19823703000722013

Oliveira, M. C. S. L., \& Madureira, A. F. A. (2014). Gênero e Psicologia do Desenvolvimento: quando a ciência é utilizada como força normatizadora das identidades de gênero. Labrys, 26, 70-79. Recuperado de https://www. labrys.net.br/labrys26/psy/maria\%20claudia.htm
Onu Mulheres, Secretaria de Políticas para Mulheres/Ministério da Mulher, da Igualdade Racial e dos Direitos Humanos, \& Secretaria Nacional de Segurança Pública/Ministério da Justiça (2016). Diretrizes para investigar, processar e julgar com perspectiva de gênero as mortes violentas de mulheres. Brasília: Autor. Recuperado de http://www. onumulheres.org.br/wp-content/uploads/2016/04/ diretrizes_feminicidio.pdf

Paim, K., \& Falcke, D. (2016). Perfil discriminante de sujeitos com histórico de violência conjugal: o papel dos Esquemas Iniciais Desadaptativos. Revista Brasileira de Terapia Comportamental e Cognitiva, 18(2), 112-129. Recuperado de http://www.usp.br/rbtcc/index.php/RBTCC/article/ view/887/483. doi: $10.31505 /$ rbtcc.v18i2.887

Porto, M., \& Bucher-Maluschke, J. S. N. F. (2014). A permanência de mulheres em situações de violência: considerações de psicólogas. Psicologia: Teoria e Pesquisa, 30(3), 267-276. Recuperado de http://www.scielo.br/pdf/ptp/v30n3/04. pdf. doi: $10.1590 / 50102-37722014000300004$

Ramos, M. E. C. (2013). Homens e mulheres envolvidos em violência e atendidos em grupos socioterapêuticos: união, comunicação e relação. Revista Brasileira de Psicodrama, 21(1), 39-53. Recuperado de http://pepsic.bvsalud.org/pdf/ psicodrama/v21n1/a04.pdf

Razera, J., \& Falcke, D. (2014). Relacionamento conjugal e violência: sair é mais difícil que ficar?. Aletheia, 45, 156-167. Recuperado de http://pepsic.bvsalud.org/pdf/aletheia/ n45/n45a12.pdf

Romagnoli, R. C. (2015a). Várias Marias: efeitos da Lei Maria da Penha nas delegacias. Fractal: Revista de Psicologia, 27(2), 114-122. Recuperado de http://www.scielo.br/ pdf/fractal/v27n2/1984-0292-fractal-27-2-0114.pdf. doi: 10.1590/1984-0292/1038

Romagnoli, R. C. (2015b). A violência contra a mulher em Montes Claros. Barbarói, 43, 27-47. Recuperado de https://online. unisc.br/seer/index.php/barbaroi/article/view/4815/4407. doi: $\underline{10.17058 / \text { barbaroi.v0i0.4815 }}$

Rosa, L. W., \& Falcke, D. (2014). Violência conjugal: compreendendo o fenômeno. Revista da SPAGESP, 15(1), 17-32. Recuperado de http://pepsic.bvsalud.org/pdf/ rspagesp/v15n1/v15n1a03.pdf.

Sá, S. D., \& Werlang, B. S. G. (2013). Personalidade de mulheres vítimas de violência doméstica: uma revisão sistemática da literatura. Contextos Clínicos, 6(2), 106-116. Recuperado de http://pepsic.bvsalud.org/pdf/cclin/v6n2/v6n2a05.pdf. doi: $10.4013 /$ ctc.2013.62.04

Sant'Anna, T. C., \& Penso, M. A. (2015). A violência contra a mulher na perspectiva da terapia feminista da família. Nova Perspectiva Sistêmica, 53, 95-110. Recuperado de http://www.revistanps.com.br/nps/article/view/149/100 
Santeiro, T. V., Schumacher, J. V., \& Souza, T. M. C. (2017). Cinema e violência contra a mulher: contribuições à formação do psicólogo clínico. Temas em Psicologia, 25(2), 401-413. Recuperado de http://pepsic.bvsalud.org/pdf/tp/v25n2/ v25n2a01.pdf. doi: 10.9788/TP2017.2-01Pt

Santos, H. M. (2016). A institucionalização da discussão de gênero no Sistema Conselhos de Psicologia. In: A. M. O. Denega, D. S. V. Andrade, \& H. Santos (orgs.). Gênero na psicologia: saberes e práticas. Salvador: CRP-03.

Secretaria de Políticas para as Mulheres do Governo do Estado da Bahia (2019). Média mensal de casos de violência contra a mulher cresce $24 \%$ em um ano [Site]. Recuperado de http:// www.mulheres.ba.gov.br/2019/02/2282/Media-mensal-decasos-de-violencia-contra-a-mulher-cresce-24-em-um-ano. html

Scarpati, A. S., Guerra, V. M., \& Duarte, C. N. B. (2014). Adaptação da Escala de Aceitação dos Mitos de Estupro: evidências de validade. Avaliação Psicológica, 13(1), 57-65. Recuperado de http://pepsic.bvsalud.org/pdf/avp/v13n1/ v13n1a08.pdf

Silva, O. M. A., Alípio, M. P. P., \& Moreira, L. E. (2016). Mulheres e violência doméstica: relato de experiência num juizado especializado. Revista Polis Psique, 6(3), 145-165. Recuperado de http://pepsic.bvsalud.org/pdf/rpps/v6n3/ n6a09.pdf

Souza, M. T., Silva, M. D., \& Carvalho, R. (2010). Revisão integrativa: o que é e como fazer. Einstein, 8(1), 102-106. Recuperado de http://www.scielo.br/pdf/eins/v8n1/pt_1679-4508eins-8-1-0102.pdf. doi: 10.1590/s1679-45082010rw1134 